\title{
DÜBLIN
}

Technological University Dublin

ARROW@TU Dublin

\section{Lane Changing Control to Reduce Traffic Load Effect on Long- Span Bridges}

\author{
Colin C. Caprani \\ Technological University Dublin, colin.caprani@tudublin.ie \\ Bernard Enright \\ Technological University Dublin, bernard.enright@tudublin.ie \\ Colm Carey \\ Technological University Dublin, colm.carey@tudublin.ie
}

Follow this and additional works at: https://arrow.tudublin.ie/engschcivcon

Part of the Civil Engineering Commons, and the Structural Engineering Commons

\section{Recommended Citation \\ Caprani, C., Carey, C. and Enright, B. (2012), 'Lane changing control to reduce traffic load effect on long-span bridges', In: F. Biondini, D.M. Frangopol, Eds, 6th International Conference on Bridge Maintenance, Safety and Management, Stresa, Italy. Taylor and Francis.}

This Conference Paper is brought to you for free and open access by the School of Civil and Structural Engineering at ARROW@TU Dublin. It has been accepted for inclusion in Conference papers by an authorized administrator of ARROW@TU Dublin. For more information, please contact arrow.admin@tudublin.ie, aisling.coyne@tudublin.ie,gerard.connolly@tudublin.ie.

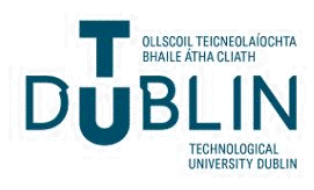




\title{
Lane changing control to reduce traffic load effect on long-span bridges
}

\author{
C. C. Caprani, B. Enright, \& C. Carey \\ Department of Civil \& Structural Engineering, Dublin Institute of Technology, Ireland
}

\begin{abstract}
Long span bridges are critical parts of a nation's infrastructure network and congested traffic loading is the governing form of traffic loading. Groups of trucks travelling in conveys are created when faster moving vehicles, such as cars, change lane. In this research the authors investigate how the control of these lane-changing events can help reduce the traffic load effects on long span bridges. Real traffic data is used to simulate a traffic stream on a virtual road and bridge using a microsimulation model. Various lane-changing restrictions are examined and compared to the typical case of free lane changing. It is shown that restriction of lane changing is an effective means of reducing long-span bridge traffic load effect. This result may assist bridge owners in implementing measures to prolong the life of existing infrastructure.
\end{abstract}

\section{INTRODUCTION}

\subsection{Motivation}

Many long-span bridges around the world were built in the early- to mid-twentieth century. Such bridges are located on arterial transport routes, by raison d'être, and as such are critically important to the economy of the region and nation they serve. However, just as these bridges are ageing and reaching the end of their design lives, the traffic loads which they support are increasing, with road freight transport typically keeping pace with economic growth (Eurostat 2009). Consequently, in the coming years, the owners of such bridges will be seeking solutions that ensure public safety whilst keeping the bridge operational. The work presented here examines a traffic load control measure that is relatively simple to implement in practice, and that may yield sufficient reduction in traffic load effect, and meet the aforementioned goals.

\subsection{Long-span bridge traffic load models}

It has long been recognized that the critical traffic loading scenario for long-span bridges is that of congested traffic (see Ivey et al. 1953 and Buckland 1981 for example). In the development of codes of practice for such bridges, researchers typically collapse the gaps between the vehicles in recorded or simulated traffic down to a minimum value. For example, in the background studies for the Eurocode, truck traffic measured from the A6 Auxerre motorway in France, was used, with gaps of $5 \mathrm{~m}$ imposed between successive vehicles (Prat 2001). Bailey (1996) used a beta distribution to model the distance between vehicles in congestion, the mode of the distribution gives a bumper-to-bumper gap of approximately $6.4 \mathrm{~m}$, with a minimum of $1.2 \mathrm{~m}$. More recently, Nowak et al. (2010) removed cars from a measured vehicle stream and imposed minimum gaps of $7.6 \mathrm{~m}$ between trucks.

The arrival of successive vehicles has generally been taken to be independent and random. This is the case in the background studies to the Eurocode (Flint \& Jacob 1996), and in the Markov process approach of Crespo-Minguillón \& Casas (1997). In a companion paper (Enright et al. 2012), we examine the importance of dependency between successive arrivals of vehicles and identify that platoons of trucks can be more common than in a purely random process. This dependency between vehicles of similar type is surely reflective of a 'sorting' of vehicles by their individual desired velocities. Since trucks often have a lower speed limit than cars, car drivers will often prefer to change lane. This phenomenon may be significant for bridge loading: if lane changing leads to higher concentrations of heavy vehicles, then its control may have the opposite effect. The present work investigates this.

\subsection{Review of traffic lane changing}

The process by which drivers decide to change lane is a complex one. Many factors are involved, including the spatial arrangement, the relative velocities with surrounding vehicles, the mechanical perfor- 
mance of the vehicle, and the psychological nature of the driver (including aggressiveness, perception, and reaction times). Yousif \& Hunt (1995) describe some of these factors, giving an intuitive explanation of the pressure to change lane, in terms of the fundamental diagram of traffic (see for example, Gartner et al. 2005), shown here as Figure 1.

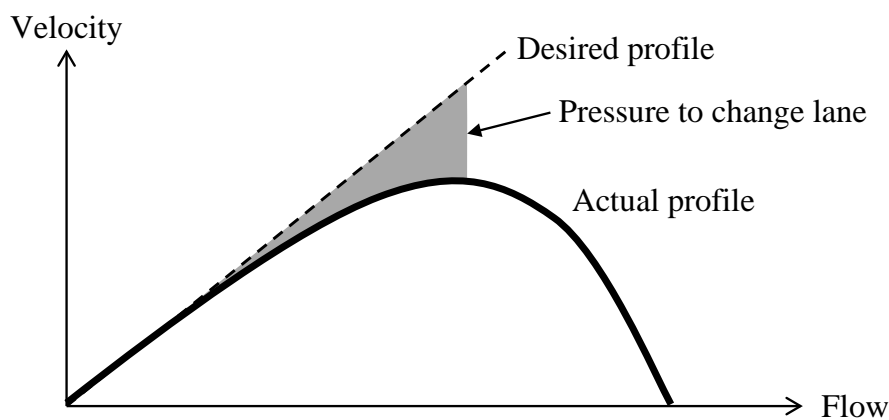

Figure 1. Relationship between the fundamental diagram of traffic and the pressure to change lane (adapted from Yousif \& Hunt 1995).

Complicating the problem of understanding lane changing further, is the difficulty in obtaining experimental data. This is because the phenomenon is spatially and temporally distributed. Attempts to monitor individual vehicle trajectories have been made (see for example, Xuan 2006, who uses Global Positioning Satellites), but suffer from the fact that the driver is aware of the monitoring.

The difficulty in determining individual vehicle's lane-changing characteristics can be somewhat overcome using empirical observations. Yousif \& Hunt (1995), Sparmann (1979), Brackstone et al. (1998), Hidas (2005) describe lane change rates as a function of flow, and these observations can be used to calibrate a lane-change model. Further efforts use other approaches, such as kinematic wave theory (Laval et al. 2006) and a gas-kinetic (Boltzmann) model (Helbing \& Greiner (1997)).

Hidas (2002 and 2005) outlines some recent work in the development of microscopic models for lane changing. The lane changing model used in this work is the microscopic MOBIL model proposed by Kesting et al. (2007) and explained later.

\section{MICROSIMULATION MODEL}

\subsection{The Intelligent Driver Model}

The Intelligent Driver Model (IDM) is a microscopic car-following model developed by Treiber and others (Treiber et al. (2000a), Treiber et al. (2000b)). Its equations describe the motion of an individual vehicle in response to its surroundings, given some physically-meaningful mechanical and driver performance parameters. In particular the IDM is based on the idea that a driver tries to minimize braking de- celerations. The acceleration a vehicle undergoes is defined by:

$$
\frac{d v}{d t}=a\left[1-\left(\frac{v}{v_{0}}\right)^{\delta}-\left(\frac{s^{*}}{s}\right)^{2}\right]
$$

which is a combination of the vehicle's acceleration towards the desired velocity, $v_{0}$, where $a$ is the maximum acceleration and $\delta$ is the velocity exponent (taken as 4), with the vehicle's decelerations due to interaction with the vehicle in front, based upon the ratio of the current gap, $s$, to the desired minimum gap, $s^{*}$, described by:

$s^{*}=s_{0}+s_{1} \sqrt{\frac{v}{v_{0}}}+v T+\frac{v(\Delta v)}{2 \sqrt{a b}}$.

in which $s_{0}$ and $s_{1}$ are the minimum and elastic jam distances respectively, $T$ is the desired time headway, $\Delta v$ is the approach velocity to the leading vehicle, and $b$ is the comfortable deceleration.

\subsection{The MOBIL lane change model}

The MOBIL lane-changing model was developed by Kesting et al. (2007) and is adopted here. Figure 2 illustrates the topology of a lane change event, where the subscript $c$ refers to the lane-changing vehicle; $o$ refers to the (proposed) old follower; and $n$ to the proposed new follower. In the following notation, the tilde refers to parameter values after the potential lane change. The vehicles in front influence the event since the accelerations of the considered vehicle $(c)$ are calculated according to the car-following model given in Equations (1) and (2).

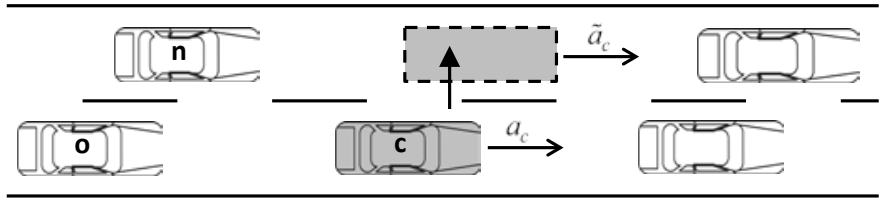

Figure 2. Vehicles involved in lane-changing manoeuvre (adapted from Kesting et al. 2007)

A lane change only occurs if two criteria are satisfied: the incentive and safety criteria. The incentive criterion determines the acceleration advantage that would be gained from the manoeuvre:

$$
\begin{aligned}
\tilde{a}_{c}(t)-a_{c}(t) \geq \Delta a_{t h}+ & \\
p & {\left[\left(a_{n}(t)-\tilde{a}_{n}(t)\right)+\left(a_{o}(t)-\tilde{a}_{o}(t)\right)\right] }
\end{aligned}
$$

Equation (3) states that the acceleration advantage to be gained by the lane-change, must be greater than both a threshold acceleration, $\Delta a_{t h}$, used to dampen out changes with marginal ad- 
vantage, and a weighted $(p)$ disadvantage to vehicles in both the current $\left(a_{o}(t)-\tilde{a}_{o}(t)\right)$ and target ( $\left.a_{n}(t)-\tilde{a}_{n}(t)\right)$ lanes. The weighting applied to the consideration of the acceleration of other vehicles is termed the politeness factor, and can be thought of as accounting for driver aggressiveness. It is this balancing of accelerations that gives rise to the name MOBIL, as Minimizing Overall Braking Induced by Lane changes.

The second criterion that must be satisfied for a lane change event to occur is the safety criterion, given by:

$\tilde{a}_{n}(t) \geq b_{\text {safe }}$

which ensures that any deceleration that would be experienced by the new follower are above a minimum safe limit, $b_{\text {safe }}$, typically taken as $-12 \mathrm{~m} / \mathrm{s}^{2}$.

The formulation as presented applies symmetrically between adjacent lanes, typical of some highways (the US for example). Asymmetric passing rules are implemented by including a bias acceleration $\Delta a_{\text {bias }}$ towards the slow lane.

\section{TRAFFIC, ROAD, \& BRIDGE DESCRIPTION}

\subsection{Traffic data}

This work uses weigh-in-motion (WIM) data obtained from the A4 (E40) at Wroclaw, Poland, shown in Figure 3. Both lanes of traffic in one direction were measured. In total 22 weeks of traffic was recorded, including cars, from 1 January 2008 to 5 June, 2008 of which 87 days of weekday traffic are suitable for further use. Weekends exhibit quite different traffic composition, and so are excluded. Trucks with up to 9 axles were measured; no trucks with more axles were observed.

Figure 4 shows the hourly flows for each day, and the overall average. Some days are unusually low due to reduced economic activity, such as 1 January for example. Figure 5 shows the corresponding traffic composition through truck percentages. Trucks are defined here as any vehicle with a Gross Vehicle Weight (GVW) over 3.5 tonnes. Again some days differ significantly in behavior from the mean.

It is clear from Figures 3 and 4 that there is a significant change in the traffic behavior and type between the hours of about 22:00 and 06:00. Clearly there are few cars, reflecting reduced personal transport, whilst commercial vehicle activity remains. This is well-explained by the transcontinental nature of the road, as evident from Figure 3.

As a result of the distinct differences in night and day traffic, this work is restricted to consideration of the daytime traffic only. The inclusion of nighttime traffic into congested traffic loading scenarios on the bridge is not done to reflect the reduced likelihood of congestion occurring at night. Thus, only traffic between the hours of 06:00 and 22:00 is considered.

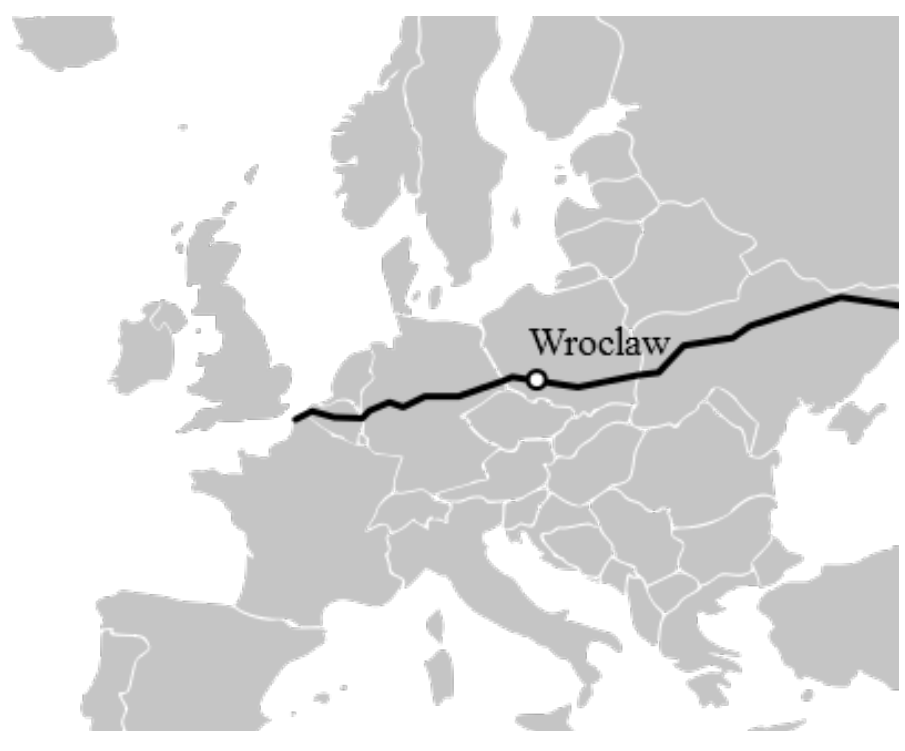

Figure 3. Weigh-In-Motion site on Autostrada A4, Euroroute E40, near Wroclaw, Poland.

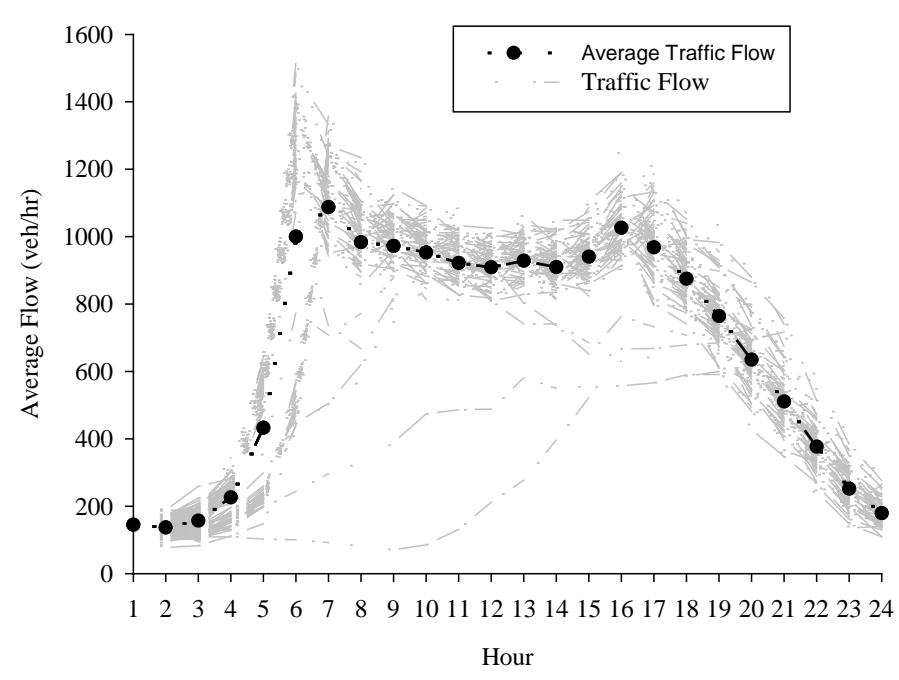

Figure 4. A4/E40 Wroclaw hourly flows.

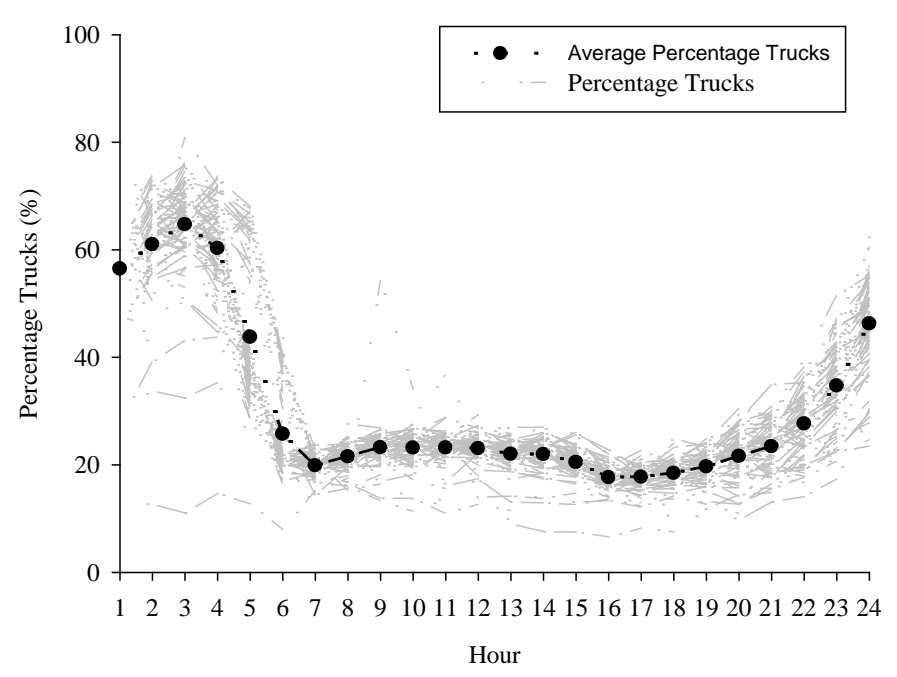

Figure 5. A4/E40 Wroclaw percentage trucks in the traffic stream. 


\subsection{Microsimulation parameters}

Table 1 gives the complete set of microsimulation variables used. The IDM parameters used in this study are taken as per Treiber (2000a). However, the desired velocity has a uniform distribution about the mean values, similarly to Kesting et al. (2007) in the development of the MOBIL model. The MOBIL parameters are taken from this paper also. A lane change minimum gap of $2.0 \mathrm{~m}$ is also ensured, and vehicles are not permitted to change lanes within $1.6 \mathrm{~s}$ of a previous lane change. This is to reflect the duration of a lane change in reality, which is carried out in a single time step in the simulation, which is $0.25 \mathrm{~s}$ as per Kesting et al. (2007).

A minimum limit of $s_{0}$ is applied when calculating $s^{*}$ for proposed lane changes from Equation (2). This is because $s^{*}$ can be negative if the front vehicle in the target lane is much faster than the vehicle considering changing lanes. This issue is acknowledged in Treiber \& Kesting (2010) and Kesting et al. (2010).

Table 1. Parameters of IDM and MOBIL models used.

\begin{tabular}{lll}
\hline & Cars & Trucks \\
\hline Desired velocity, $v_{0}$ & $\begin{array}{l}120 \mathrm{~km} / \mathrm{h} \\
( \pm 20)\end{array}$ & $\begin{array}{l}80 \mathrm{~km} / \mathrm{h} \\
( \pm 20)\end{array}$ \\
Safe time headway, $T$ & $1.2 \mathrm{~s}$ & $1.7 \mathrm{~s}$ \\
Maximum acceleration, $a$ & $0.80 \mathrm{~m} / \mathrm{s}^{2}$ & $0.40 \mathrm{~m} / \mathrm{s}^{2}$ \\
Comfortable deceleration, $b$ & $1.25 \mathrm{~m} / \mathrm{s}^{2}$ & $0.80 \mathrm{~m} / \mathrm{s}^{2}$ \\
Minimum jam distance, $s_{0}$ & $1.0 \mathrm{~m}$ & $1.0 \mathrm{~m}$ \\
Elastic jam distance, $s_{1}$ & $10.0 \mathrm{~m}$ & $10.0 \mathrm{~m}$ \\
Politeness factor, $p$ & 0.25 & 0.25 \\
Changing threshold, $\Delta a_{\text {th }}$ & $0.1 \mathrm{~m} / \mathrm{s}^{2}$ & $0.14 \mathrm{~m} / \mathrm{s}^{2}$ \\
Maximum safe deceleration, $b_{\text {safe }}$ & $12 \mathrm{~m} / \mathrm{s}^{2}$ & $12 \mathrm{~m} / \mathrm{s}^{2}$ \\
Bias for the slow lane, $\Delta a_{\text {bias }}$ & $0.30 \mathrm{~m} / \mathrm{s}^{2}$ & $0.3 \mathrm{~m} / \mathrm{s}^{2}$ \\
\hline
\end{tabular}

\subsection{Road configuration}

A $10 \mathrm{~km}$ long two-lane single-direction virtual road is used in this work. Vehicles are injected at the start of this road, according to their site-measured timestamps. They are then simulated 'driving' this road using the IDM and MOBIL models. Congestion is induced throughout each day of traffic through use of a strong inhomogeneity at $9.50 \mathrm{~km}$ : a speed-limit of $20 \mathrm{~km} / \mathrm{h}$ and an increase in the safe-time headway of $0.5 \mathrm{~s}$ is applied to all vehicles. The start of each of the bridges considered for this study is located at $8.25 \mathrm{~km}$. Congestion then builds, propagating backwards from $9.50 \mathrm{~km}$, at a typical speed of about 12$15 \mathrm{~km} / \mathrm{h}$. Due to the gaps in the input traffic stream between 22:00 and 06:00 the next day, this induced congestion clears. As a result, each day is considered independent and identically distributed.

\subsection{Bridges and load effects considered}

The bridges considered for this work are $200 \mathrm{~m}, 500$ $\mathrm{m}$ and $1 \mathrm{~km}$ long. The total load on the bridge is considered as the load effect. An equivalent uniformly distributed load is then easily established, as is common for long-span bridge load models (see Buckland 1981 for example).

\section{LANE CHANGE SCENARIOS \& RATES}

\subsection{Lane change scenarios considered}

To investigate the impact of possible lane-change restrictions zones on bridge loading, a range of scenarios are examined, as given in Table 2. The benchmark scenario of no lane change control is considered (Scenario 1), as is the case in which no lane change at all is permitted (Scenario 2). These two scenarios should provide the extremes of the impact. In particular, the complete restriction of lane changes in Scenario 2 prevents the filtering of vehicles by desired velocity that could lead to truck platoons forming. Thus, Scenario 2 should provide the lower bound load effects, whilst Scenario 1 provides the upper. Intuitively then, the results of Scenarios 3-5 should therefore lie between these bounds.

Table 2. Scenarios of lane change control considered.

\begin{tabular}{ll}
\hline Scenario & Lane Change Restriction \\
\hline 1 & None \\
2 & Complete \\
3 & $1.0 \mathrm{~km}^{*}$ \\
4 & $2.5 \mathrm{~km}^{*}$ \\
5 & $5.0 \mathrm{~km}^{*}$ \\
\hline$*$
\end{tabular}

* Ends at the start of the bridge at $8.25 \mathrm{~km}$

\subsection{Lane change rates}

To examine the lane change behavior of the traffic under the various scenarios considered, a 10-day sample is analyzed in detail for the spatio-temporal distribution of lane changes. The lane change rates (events per km per hour) are found at $500 \mathrm{~m}$ intervals and at 30 minute intervals. From this sample set, the daily average spatio-temporal distribution of lane change rates are determined for each of the scenarios, and are given in Figure 6.

From Figure 6, it can be seen that for each scenario, there is relatively high lane change at the entrance to the virtual road (0-0.5 km) for all hours. This reflects the activity following superposition of the model parameters onto the WIM-measured vehicles. Ideally there should be a perfectly smooth transition from measured-to-virtual road behavior. However, its influence dissipates at about $1 \mathrm{~km}$. 


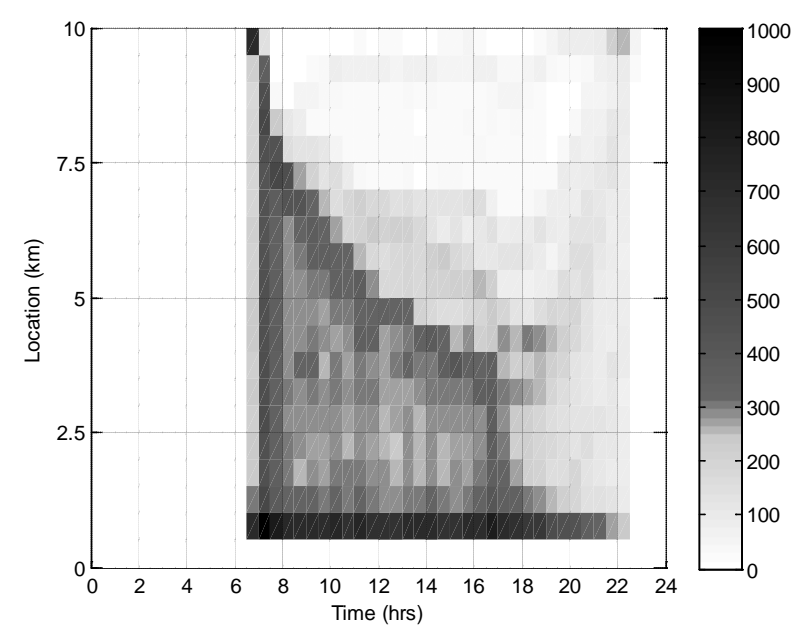

(a) Scenario 1 - no lane change restriction

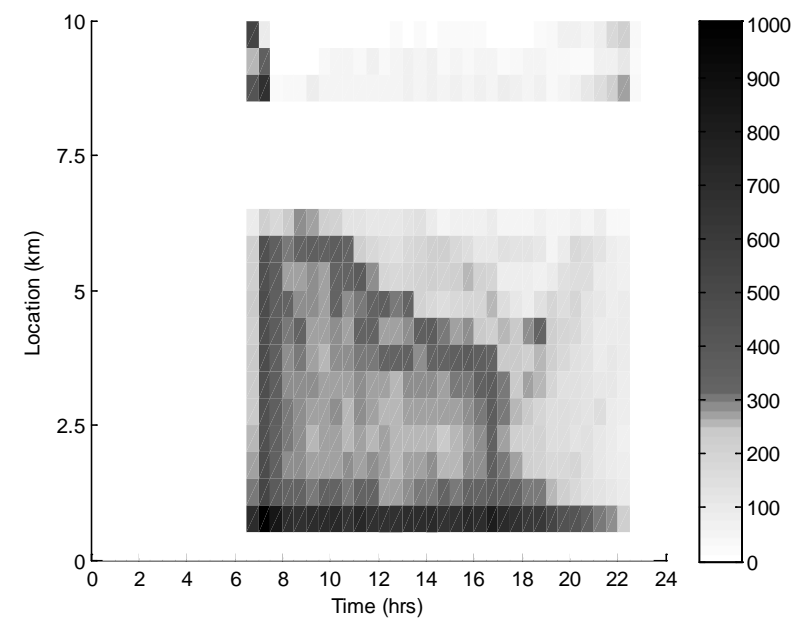

(c) Scenario $4-2.5 \mathrm{~km}$ lane change restriction $(5.75-8.25 \mathrm{~km})$

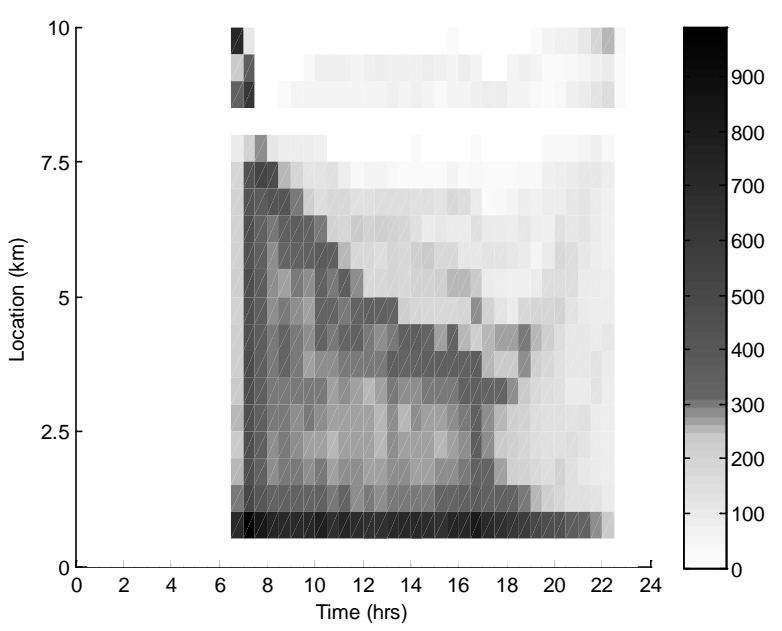

(b) Scenario 3 - $1 \mathrm{~km}$ lane change restriction $(7.25-8.25 \mathrm{~km})$

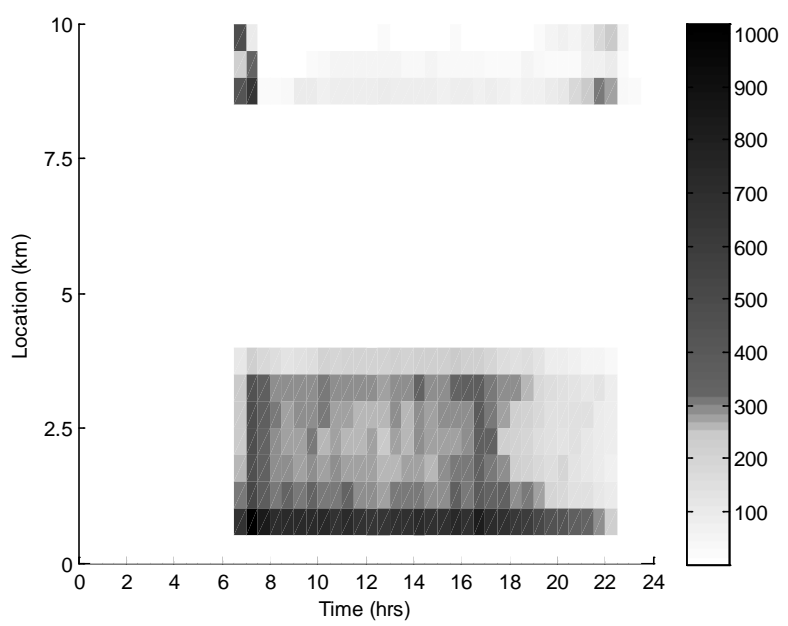

(d) Scenario 5 - $5 \mathrm{~km}$ lane change restriction $(3.25-8.25 \mathrm{~km})$

Figure 6. Spatio-temporal distribution of lane change rates (events/km/hour) for different lane change restriction scenarios.

Figure 6 also shows approximately constant lane change rate along the length of the road from about 06:00-07:00. This reflects free-flow driving behaviour due to the empty road in front of the injected vehicles. The breakdown to congested flow is then clearly evident for each of the scenarios as a diagonal band of high lane change rate, propagating backwards in space at about $1 \mathrm{~km} / \mathrm{h}$. Lane change rates beyond this 'wave front' are very small, and this is typical of heavily congested flow. Of course, there are no lane changes in the lane change restriction zones or when there is no traffic, which are the horizontal and vertical white areas respectively. However, also apparent is the high lane change rates at the end of the lane change restriction zones, and at the entrance to the inhomogeneity at $9.50 \mathrm{~km}$. This reflects the recommencement of the sorting of vehicles by desired velocity. However, it is constrained somewhat by the inhomogeneity at $9.50 \mathrm{~km}$, which controls the desired velocities upon entry to this zone.

\section{LOAD EFFECT RESULTS}

\subsection{Statistical analysis of load effects}

The maximum total load recorded on the bridge during any 24 hour period is considered as the basis for a block maximum extreme value analysis. Preliminary investigation of this data was carried out. Days of zero data such as weekends were removed. Histograms were used to identify outlier data, an example is shown in Figure 7. The large load effect (> $8 \mathrm{MN}$ ) in Figure 7 was found to be from erroneous data (in spite of careful WIM data cleaning), of four 55+ tonne 2-axle vehicles. This was removed from further analysis. Low values of load effect were also excluded, as these arise from days of low flow (for example, New Year's Day, 1 January 2008) and so congestion does not occur. Such data points do not belong to the same statistical generating mechanism, and so can bias the results non-conservatively. For example, only data above $2.5 \mathrm{MN}$ was considered for the case shown in Figure 7. 


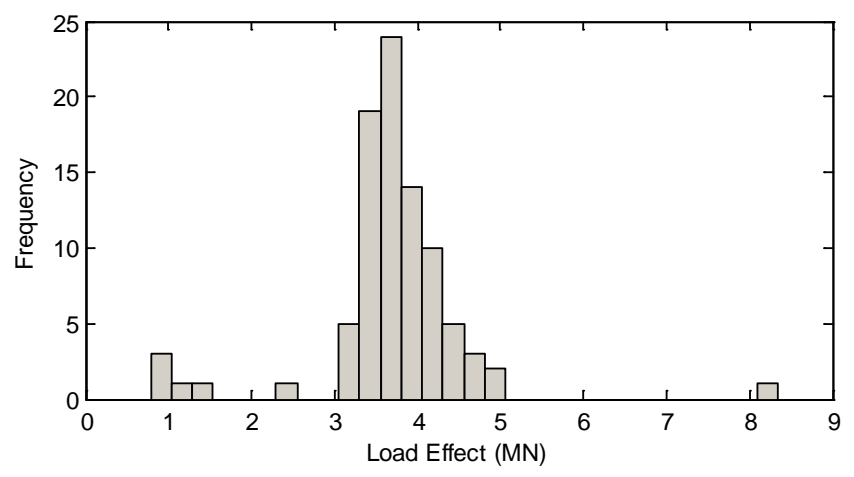

Figure 7. Exploratory data analysis for a $200 \mathrm{~m}$ bridge with no lane change control (Scenario 1).

The distribution of the maximum of data from an independent and identically distributed parent population can be shown to be given by the Generalized Extreme Value distribution (Coles 2001):

$G(s)=\exp \left\{-\left[1-\xi\left(\frac{s-\mu}{\sigma}\right)\right]_{+}^{1 / \xi}\right\}$

where $[h]_{+}=\max (h, 0)$ and $\mu, \sigma, \xi$, are the location, scale and shape parameters respectively. The parameters are estimated using maximum likelihood. This distribution then forms the basis for an extrapolation to characteristic values of load effect. An example extrapolation is shown in Figure 8. A 1000-year return period (approximately 5\% probability of exceedance in 50 years) is considered as this is similar to that of the Eurocode (EC1.2 2003) for design, and a 75-year return period is considered as one suitable for bridge assessment.

It should be noted that since congestion is induced throughout the day, the extrapolation of the resulting load effects to return periods of 75- and 1000 -years will give conservative load effects. This is because long-span bridges typically may have only 1 or 2 hours of heavy congested traffic per day, if even this much.

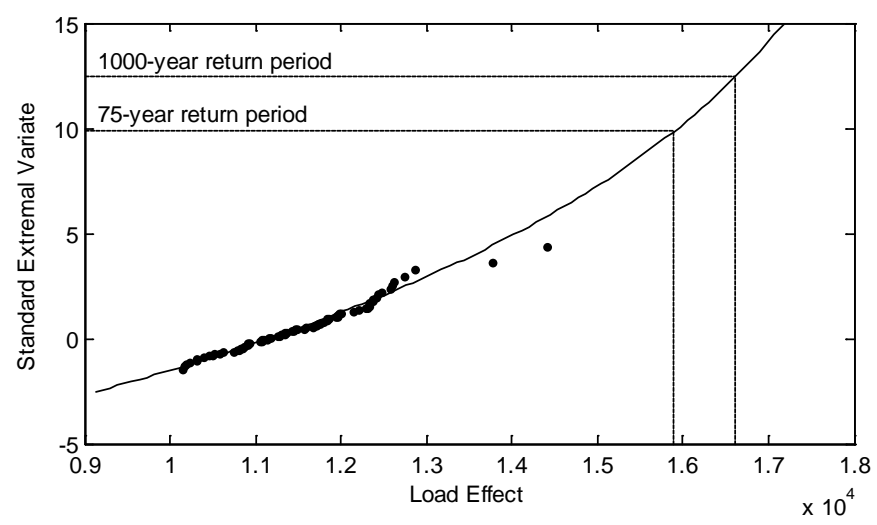

Figure 8. Example extrapolation of data to 75- and 1000-year return periods.

\subsection{Results}

Figure 9 gives the extrapolated load effect results for each bridge length and lane change control scenario examined. To compare the different scenarios more easily, the ratio of the 1000-year values were compared to the uncontrolled results (Scenario 1), shown in Figure 10, and given in Table 3.

The results show that Scenario 2 load effects are significantly lower than the uncontrolled case. This means that lane change control is an effective strategy for reducing bridge load effect.

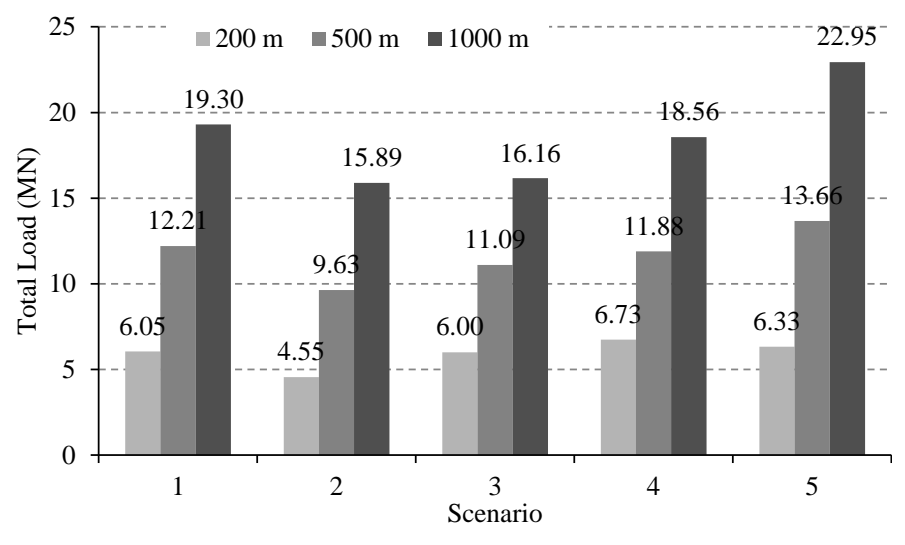

(a) 75-year load effects for each scenario;

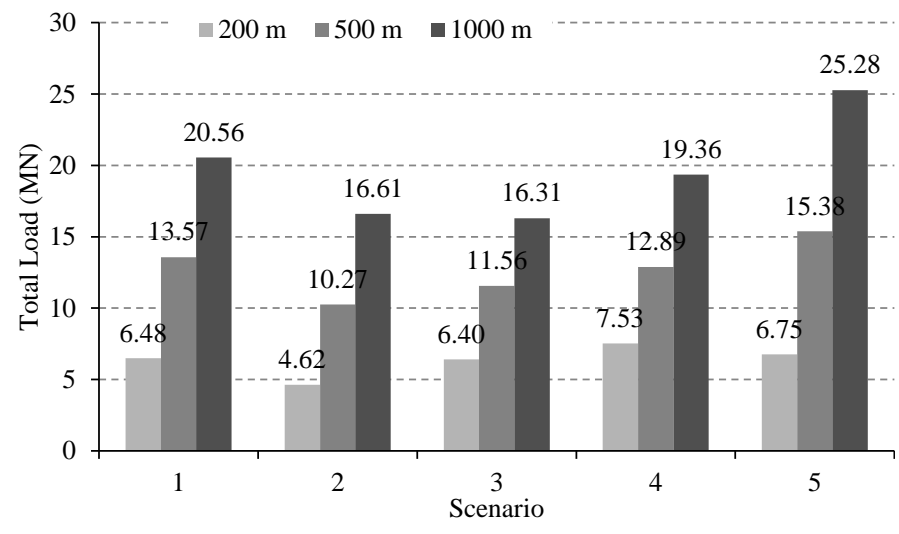

(b) 1000-year load effects for each scenario;

Figure 9. Load effects for each scenario and return period.

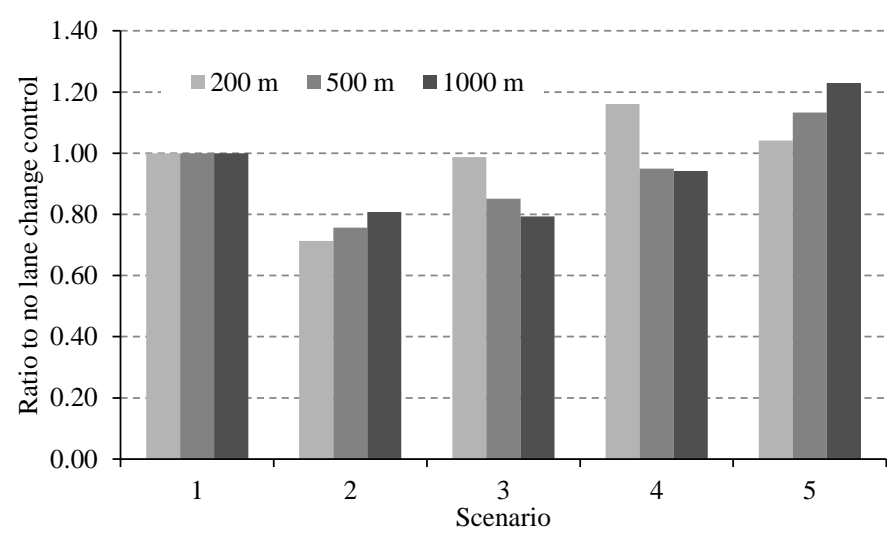

Figure 10. Ratios of 1000-year load effect resulting from lane change control scenarios (2-5), compared to no lane change control (1). 
Table 3. Ratios of 1000-year load effect resulting from lane change control scenarios (2-5), compared to no lane change control (1).

\begin{tabular}{llll}
\hline \multirow{2}{*}{ Scenario } & \multicolumn{3}{l}{ Bridge } \\
\cline { 2 - 4 } & $200 \mathrm{~m}$ & $500 \mathrm{~m}$ & $1000 \mathrm{~m}$ \\
\hline 1 & 1.00 & 1.00 & 1.00 \\
2 & 0.71 & 0.76 & 0.81 \\
3 & 0.99 & 0.85 & 0.79 \\
4 & 1.16 & 0.95 & 0.94 \\
5 & 1.04 & 1.13 & 1.23 \\
\hline
\end{tabular}

For scenarios 3,4 , and 5 , the results indicate that the implementation of lane-change control requires careful consideration. The $5 \mathrm{~km}$ lane change restriction zone (Scenario 5) actually increased load effect on all bridges, whilst the $1 \mathrm{~km}$ zone (Scenario 3) showed good-to-little reduction. These results are counter-intuitive and so require further exploration.

\subsection{Analysis of results}

To explain the observed results, the total density on the two-lane road of vehicles at the bridge entrance $(8.25 \mathrm{~km})$ and load effect are plotted in Figure 11 for the $1000 \mathrm{~m}$ bridge and Scenario 3, for a sample week. There is clearly a strong relationship between the two series, with load effect peaks corresponding to multiple-truck occurrences which do not alter density.

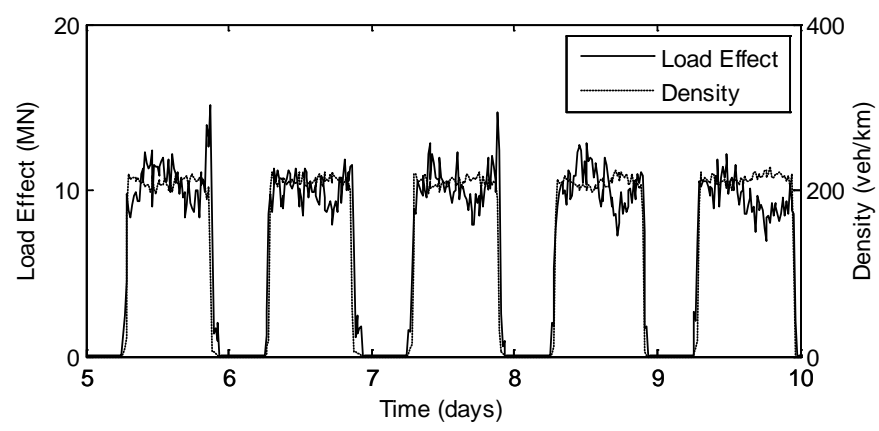

Figure 11. Density at bridge entrance and load effect for Scenario 3, $1000 \mathrm{~m}$ bridge. (Note: daytime traffic only is used.)

As a result of this strong relationship, spatiotemporal plots of density are given in Figure 12 for both Scenarios 3 and 5. Density is calculated at $500 \mathrm{~m}$ space intervals and at 15-minute time intervals. The times for which no traffic occurs are easily seen (white areas), as is the build-up of congestion throughout the day (black areas).

From Figure 12 it is clear that traffic density is relatively unaffected by the $1 \mathrm{~km}$ control zone, since breakdown to congestion occurs further back down the road, as the day goes on. Thus this shorter zone only influences lane-changing once congestion is already present. Conversely, the $5 \mathrm{~km}$ zone is longer than the typical build-up of congestion and so density cannot increase due to lane-changing, but only due to longitudinal compression of the traffic stream. Since drivers generally maintain safe distances, the density within the $5 \mathrm{~km}$ lane-change restriction zone then remains at medium levels (about $40 \%$ capacity). However, once the restriction zone is lifted, density quickly builds (at $8.5 \mathrm{~km}$ ) due to lane changing (see Figure 6(d)) and this influences the load on the bridge significantly.

The lower density of traffic observed within the 5 $\mathrm{km}$ lane change restriction zone suggests that the zone should be placed so as to include the bridge. With reduced density, reduced load effect may also be found (see Figure 11). However, the rapid change in density (no grey area) when lane change control is not influencing the traffic (Figure 12(a)) arises from drivers minimizing travel time (Figure 1). The results of Figure 12(b) then suggest that the medium densities observed within the zone correspond to increased travel time.

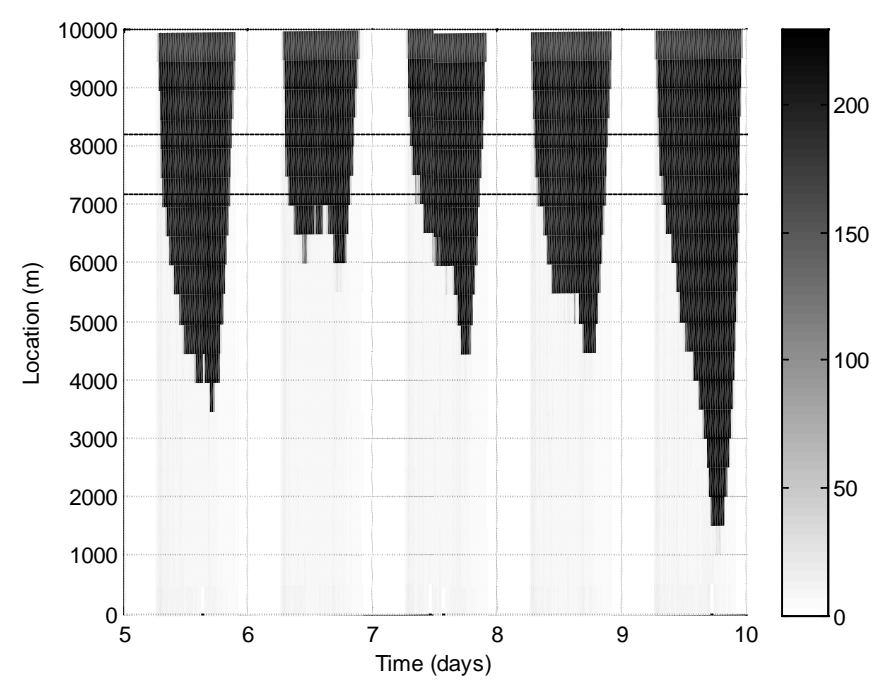

(a) Scenario 3: $1 \mathrm{~km}$ lane change control zone;

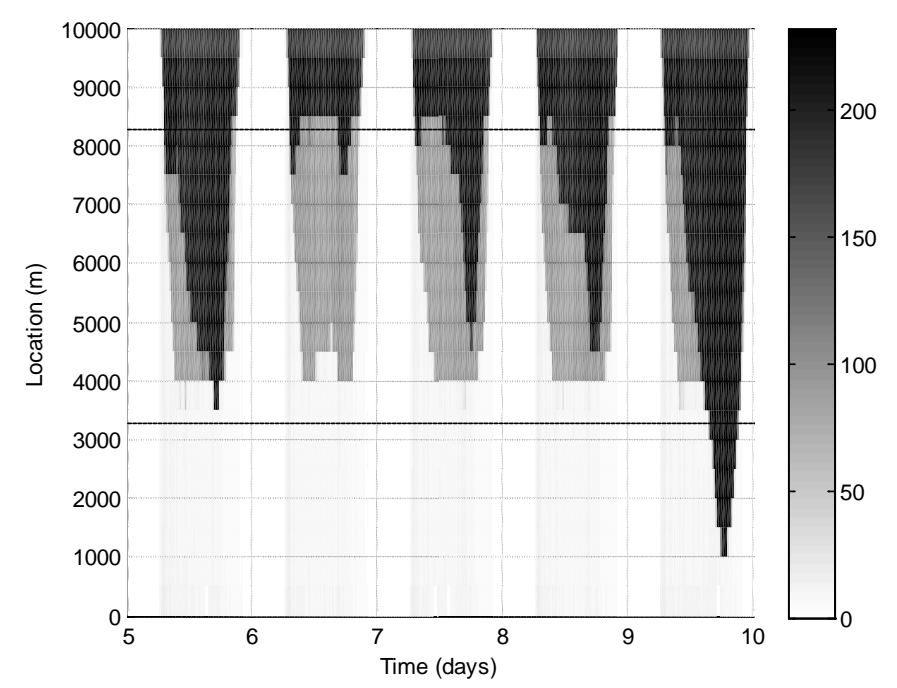

(b) Scenario 5: $5 \mathrm{~km}$ lane change control zone;

Figure 12. Spatio-temporal density (vehicles/km) for 5 days' data for different lane change control zones (start and end of zones shown as dashed lines). 


\section{SUMMARY AND DISCUSSION}

\subsection{Summary}

An investigation into the effectiveness of lanechange control in reducing bridge traffic load effect is presented. Weigh-in-motion data from a site on a transcontinental highway is used as the basis for the study. Microsimulation of traffic is used to model driving behavior accurately, as congestion is induced, and drivers respond. Severe congestion is induced in the measured traffic and the resulting bridge traffic load effect determined for a range of bridge lengths. A range of lane change control scenarios are considered and compared to the donothing scenario. Results are presented for 75-year (assessment) and 1000-year (design) return periods.

It is found here that complete elimination of lane changing on the simulated road (Scenario 2) results in reductions of load effect of about 20-30\%. For the short $1 \mathrm{~km}$ zone of lane change control, the results also show a reduction in load effect. For the longer 5 $\mathrm{km}$ lane change restriction zone, load effects are found to increase.

\subsection{Discussion}

The results of this work show that lane-change control can be an effective means of reducing long-span bridge traffic load effect. However, the effectiveness is sensitive to the means of controlling the lane changing, and may even increase the traffic load effect. The results also indicate that the lane-change control can reduce the density of traffic within the zone, once it is introduced before the traffic breaks down to congested flow. It is clear that whilst the concept may prove valuable, further work is required. It is also clear that microsimulation, coupled with complete and long-duration traffic records, is a valuable asset in exploring methods of increasing the useful lifespan of ageing infrastructure.

\section{ACKNOWLEDGEMENT}

The authors would like to acknowledge the Dublin Institute of Technology ABBEST Scholarship Programme for supporting this research.

\section{REFERENCES}

Bailey, S.F. 1996. Basic Principles and load models for the structural safety evaluation of existing bridges, Ph.D. Dissertation, Thesis No. 1467, École Polythechnique Fédéral de Lausanne, Switzerland.

Brackstone, M., McDonald, M., Wu, J. 1998. Lane changing on the motorway: factors affecting its occurrence, and their implications. In: 9th International Conference on Road Transport Information and Control, London, UK.

Buckland, P.G. 1981. Recommended design loads for bridges (Committee on loads and forces on bridges of the commit- tee on bridges of the structural division), Journal of the Structural Division, ASCE: 1161-213.

Coles, S.G. 2001. An Introduction to Statistical Modelling of Extreme Values. London: Springer-Verlag.

Crespo-Minguillón, C. \& Casas, J.R. 1997. A Comprehensive traffic load model for bridge safety checking, Structural Safety 19: 339-359.

EC1.2. 2003. Eurocode 1: Actions on Structures, Part 2: Traffic loads on bridges, European Standard EN 1991-2: European Committee for Standardisation, Brussels.

European Commission Directorate-General for Energy, Transport and Environment Indicators. 2009. European Union Energy and Transport in Figures 2009.

Flint, A.R. \& Jacob, B.A. 1996. Extreme traffic loads on road bridges and target values for their effects for code calibration. In Procs. of IABSE Colloquium Basis of Design and Actions on Structures,, IABSE, Delft: 469-477.

Gartner, N.H., Rathi, A.J., \& Messer, C.J. (Eds.) 2005. Revised Monograph on Traffic Flow Theory: A State-of-the-Art Report, Turner-Fairbank Highway Research Center, Federal Highway Administration.

Helbing, D. \& Greiner, A. 1997. Modeling and simulation of multi-lane traffic flow. Physical Review E, 55: 5498-5508.

Hidas, P. 2002. Modelling lane changing and merging in microscopic traffic simulation, Transportation Research Part C: Emerging Technologies, 10(5-6): 351-371.

Hidas, P. 2005. Modelling vehicle interactions in microscopic simulation of merging and weaving. Transportation Research Part C: Emerging Technologies 13(1): 37-62.

Ivy, R.J., Lin, T.Y., Mitchell, S., Raab, N.C., Richey V.J. \& Scheffey, C.F. 1953. Live loading for long-span highway bridges. ASCE Trans., Paper No. 3708, 119: 981-1004.

Kesting, A, Treiber, M., \& Helbing, D. 2010. Enhanced Intelligent Driver Model to access the impact of driving strategies on traffic capacity, Philos. Trans. Royal Soc. A 368: 45854605.

Kesting, A., Treiber, M. \& Helbing D. 2007. General lanechanging model MOBIL for car-following models. Transportation Research Record: Journal of the Transportation Research Board, 1999: 86-94.

Laval, J.A. \& Daganzo, C.F. 2006. Lane-changing in traffic streams. Transportation Research Part B: Methodological 40(3): 251-264.

Nowak, A.S., Lutomirska, M. \& Sheikh Ibrahim, F.I. 2010. The development of live load for long-span bridges. Bridge Structures - Assessment, Design \& Construction. 6(1-2): 73-79.

Prat, M. 2001. Traffic load models for bridge design: recent developments and research. Progress in Structural Engineering and Materials 3: 326-334.

Sparmann, U. 1979. The importance of lane-changing on motorways. Traffic Engineering and. Control, 20(6): 320-323.

Treiber, M., Hennecke, A., \& Helbing, D. 2000a. Microscopic Simulation of Congested Traffic. in: Traffic and Granular Flow '99, Eds. D. Helbing, H.J., Herrmann, M. Schreckenberg, \& D.E. Wolf, Springer, Berlin: 365-376.

Treiber, M., Hennecke, A. \& Helbing, D. 2000b. Congested Traffic States in Empirical Observations and Microscopic Simulations. Physical Review E, 62(2): 1805-1824.

Treiber, M. \& Kesting, A. 2010. An open-source microscopic traffic simulator, Intelligent Transportation Systems Magazine, IEEE, 2(3): 6-13.

Xuan, Y. 2006. Lane Change Maneuver Detection from Probe Vehicle DGPS Data, Proceedings of the 2006 IEEE Intelligent Transportation Systems Conference, Toronto, Canada, September 17-20: 624-629.

Yousif, S. \& Hunt, J. 1995. Modelling lane utilisation on British dualcarriageway roads: effects on lane-changing. Traffic Engineering and. Control 36(12): 680-687. 